\title{
"All the World's a Stage": A GIS Framework for Recreating Personal Time-Space from Qualitative and Quantitative Sources
}

\author{
Don Lafreniere* and Jason Gilliland ${ }^{+}$ \\ *Department of Social Sciences, Michigan Technological University \\ ${ }^{\dagger}$ Department of Geography, University of Western Ontario
}

\begin{abstract}
This article presents a methodological model for the study of the space-time patterns of everyday life. The framework utilizes a wide range of qualitative and quantitative sources to create two environmental stages, social and built, which place and contextualize the daily mobilities of individuals as they traverse urban environments. Additionally, this study outlines a procedure to fully integrate narrative sources in a GIS. By placing qualitative sources, such as narratives, within a stage-based GIS, researchers can begin to tell rich spatial stories about the lived experiences of segregation, social interaction, and environmental exposure. The article concludes with a case study utilizing the diary of a postal clerk to outline the wide applicability of this model for space-time GIS research.
\end{abstract}

\section{Introduction}

Set design is an important consideration for any play, movie, or theatrical endeavor. Visual imagery is critical to capturing the audience's attention and placing them within the scene created for them. A well designed set allows an audience to apprehend important contextual clues about the world-view being presented. If a film-maker were telling the story of the First World War's Battle of Polygon Wood, the backdrop would include a vivid recreation of the fallen woodlot with its miles of trenches and mud, not the modern four-lane A19 motorway that traverses much of the former Ypres Salient.

As geographers, we find it important to tell not only where an event occurs, but how the space in which a geographical phenomenon operates can influence outcomes. We need an understanding of the environment in which an activity, event, or phenomenon occurs. In geographical research, the environment may be social, physical, or ecological, and often is a combination of these.

Human geographers find it fundamental to have an understanding of the social environment; be it sociological, economic, or political. We often begin by creating a profile of the demographic characteristics and composition of the population we are studying. The demographic profile typically includes a combination of variables extracted from a census sample or similar survey that represents the nocturnal population. To adhere to the demands of research ethics, these samples are traditionally aggregated to arbitrary geographies such as census tracts.

However, neither environments nor actors are static. Environments are created and continually modified, both physically and socially, by the actors who use them. Actors are mobile, not only residentially mobile, but continuously mobile as they move through their daily lives. 
These daily time-space patterns have provided countless lines of enquiry for geographers over the past half-century, with topics ranging from racial and ethnic segregation to labor markets, and from health outcomes to community cohesion.

Kwan (2013) has recently argued that we need to expand our analytical focus from the static residential spaces captured in census-based studies to other places and times in people's daily lives. She suggests that a deeper understanding of a population's spatio-temporal experiences could be established if we study "where and when people work, eat, play, shop, and socialize" (Kwan 2013, p.6). Congruent with her theoretical framework, this article will outline a methodological framework to study the space-time patterns of everyday life using a wide range of qualitative and quantitative sources.

We argue in this article that when studying the spatio-temporal patterns of individuals, a stage must first be set in which to place and contextualize the space-time paths and social interactions. This means going beyond merely putting one layer of space-time data atop another, or placing the paths against a backdrop such as Google Earth, as these common approaches decontextualize the data. Instead, we argue that space-time data should be contextualized on a set of rich environmental stages constructed using a wide range of qualitative and quantitative sources such as temporally representative maps, social surveys, photographs, and local property data. We advocate the creation of a GIS where sources are fully integrated with the contextualizing stage, going beyond the simple recognition that they share the same geographic and temporal space.

This article provides a detailed framework for the creation of two environmental stages, built and social. A built environment stage comprises data sources that allow for the modeling of the human-made spaces in cities, including the structures, land uses, transportation systems and parks. These are the physical spaces in which people live, work, play, and the domain with which researchers of individual space-time patterns have largely been concerned. A social environment stage comprises a dataset of all residents of the city, at the scale of the individual, complete with their full socio-demographic characteristics. It includes their familial, workplace, school, and religious affiliations and networks. This allows for the modeling of the social structures and social relations that shape the everyday lives of individuals. The social environment is also their community, the racial "the wrong side of the tracks", or their " "hood". It allows for the uncovering of the socially constructed places in the city such as "eastside", "westside", or "uptown". It also encompasses micro-scale social environments such as families, co-workers, classmates, and congregations.

In addition to laying out the framework for a stage-based GIS, this article makes an attempt to integrate narrative sources in a GIS. By utilizing data-rich environmental stages, we have created a methodology that allows narrative sources to be used in a GIS in concert with, and contextualized by, traditional quantitative data. This framework affords researchers the ability to not only georeference non-tabular sources, such as narratives, within a GIS but also to maintain and even add important contextual clues. Additionally, by integrating this approach with the environmental stages, a deeper understanding of the spaces recorded in the narrative can be achieved than by examining the text alone. We can interrogate both the physical and social spaces occupied not only by the writer but also by each and every person he or she mentions in his or her daily account of life in the city. We can map not only the physical spaces occupied by the diary writer and his or her relations, but also the social networks of friendship, family, and business. This new framework for a space-time GIS allows for the creation of rich spatial stories and a more robust and accurate interpretation of the space-time patterns of past populations, the places they created, and the larger social environments present in urban areas. 


\section{Related Work}

In recent years, an interdisciplinary mass of scholars has turned its attention to the use and potential of GIS as a research tool to dissect and analyze qualitative sources (Kwan and Ding 2008; Jung 2009; Jung and Elwood 2010; Cooper and Gregory 2011). This attention can be attributed to both the increasing data-handling abilities of a desktop GIS and the potential for spatially statistically rich mixed-methods insight that can be acquired through the use of a GIS. To date, the use of qualitative sources in a GIS has centered primarily in participatory GIS (PPGIS), where the prime concern has been to enfranchise local knowledge (Craig et al. 2002; Rambaldi et al. 2006; Corbett and Rambaldi 2009; Loebach and Gilliland 2010; Cowan et al. 2012) or as an epistemology for capturing non-cartographic forms of spatial information (Kwan 2007; Elwood 2009b; Dennis et al. 2009; Koti 2010). The potential of qualitative GIS has begun to catch the interest of a range of scholars who have embraced the "spatial turn" in the social sciences and humanities (Bodenhamer et al. 2010; Dear et al. 2011).

This newest crop of spatial thinkers has been inspired by the possibilities promoted by those who have adopted GIS for historical research. Early work in the blossoming discipline of Historical GIS (HGIS) was focused largely on the creation of national HGIS datasets that spatialized aggregated collections of tabular government sources such as censuses (Gregory et al. 2002; McMaster and Noble 2005; St-Hilaire et al. 2007), administrative boundaries (De Moor and Wiedemann 2001; Kunz and Boehler 2005; Bol 2008) and toponyms (Berman 2004; Mostern and Johnson 2008; Southall et al. 2011). Other projects utilized individuallevel nominal sources such as city directories, censuses, and tax rolls to create datasets at the local scale (Debats 2008; 2009; Gilliland and Olson 2003; 2010; Dunae et al. 2011; Novak and Gilliland 2011; Lutz et al. 2013). Only recently have HGIS scholars attempted to incorporate written texts, such as travel diaries or recollections of an event in a newspaper, into a

geospatial environment. Most notable is the work by Ian Gregory and his colleagues, who have begun to extract spatial and temporal cues from corpuses of newspapers and travel accounts (Gregory and Cooper 2009; Cooper and Gregory 2011; Gregory and Hardie 2011). These early efforts show that the incorporation of written texts into a GIS is of interest to humanities researchers; however, they involve little more than mapping place names with the aid of a gazetteer.

It has been noted that there is a "challenge of including local knowledge in GIS-based data structures and GIS-based analysis, because it is often represented in forms such as texts..." (Jung 2009, p. 118). We suggest that a deeper understanding of space- and place-making can be captured from a corpus of written texts. It requires an integration of the spatial cues found within a text with a deep understanding of the local environment to which the text refers. A further challenge is georeferencing textual data that is expressed solely using situational relationships, such as the "new mill near where the river bends" or "the vacant lot on First Street by the abandoned factory". Yao and Jiang (2005), Yao and Thill (2006), and Jung and Elwood (2010) have pioneered techniques for such "qualitative locations", allowing for the visualization of textual sources that do not have absolute Euclidean geometries. These important methodological contributions will aid researchers in using GIS to visualize, quantify, and interrogate constructions of place and time.

What is missing from current qualitative GIS research, and is of interest to researchers both within and outside of traditional GIS circles, is the maintenance of the contextual cues that lie within many textual sources. What we present here is a framework for using a GIS for the contextualization of qualitative sources, particularly texts, beyond just locating their point 
or extent on a map. We see this integration of texts as allowing researchers not only to fully utilize the data-handling and analytical capabilities of a GIS for qualitative sources, but also to recreate the space-time paths, or spatial stories, of a large number of individuals with relative ease.

\section{Building Geospatial Stages}

This article outlines the GIS framework and data structures created during the nearly decadelong creation of the Imag(in)ing London Historical GIS Project. Our HGIS, spanning 18712013, has been built to be robust and flexible both in the sophistication of the spatial analysis techniques that can be employed and in the range of sources that can be incorporated. This allows for a deep contextualization of both the quantitative and qualitative sources that are brought into the system.

Our HGIS is comprised of two stages, a built environment stage and a social environment stage. Each stage is designed and built to be independent of the other, both spatially and temporally, but are used in concert to perform queries and analysis. Each is built using the spatial references from a specific temporal period recorded in an archival cartographic source. Further, each stage is comprised of many "scenes", or temporal periods represented. We have built environment "scenes" that represent the entire city of London, Ontario and its suburbs for 1855, 1881, 1888, 1907, 1915, 1926, 1958, and 2008-2013.

\subsection{The Built Environment Stage}

The foundation of a built environment scene could be any historical source or combination of sources that captures a comprehensive representation of the past landscape, such as a topographic map, geodetic survey, or fire insurance plan (FIP). Our first built environment scene began with the 1881 FIP of London created by the Charles E. Goad Company. Goad produced FIPs for most major cities in Canada and Great Britain from 1878-1970 (Goad 1984). Similar to those produced by the American Sanborn Map Company, the plans were created to aid fire insurance companies in assessing risk. FIPs have long been recognized for their accuracy and immense detail on the built environment of the city (Bloomfield 1982; Krafft 1993; Oswald 1997). Each building's use, number of floors, construction material, and position within the lot are documented with a cartographic precision of 1:6,000. The height of larger buildings is often recorded, along with the use of individual rooms and the location of fire hazards such as furnaces, wood piles, oil tanks, and generators (Figure 1). This impressive cartographic record provides researchers who study the late 19 th to mid-20th century with an ideal source for the construction of a built environment scene.

Our work began with the digitalization of the historical cartographic sources using a large format scanner at a resolution of 1,200 DPI (see Figure 2). The images were then georeferenced to a modern GIS of the city using ArcGIS 9.2. To include the built environment variables found on the FIPs, each building needed to be vectorized by hand. Although time-consuming, this step was critical so that we could perform spatial analytic queries on the built environment and allows for the contextualization of space-time data that we are advocating (Figure 1). Thankfully, several researchers are developing techniques to automate the extraction of built environment variables from cartographic and remotely sensed images (Carneiro et al. 2010; Aldred and Wang 2011; Marciano et al. 2013). Despite recent advances in autovectorization, there is still the need to assign the environmental attributes noted on the FIPs to 

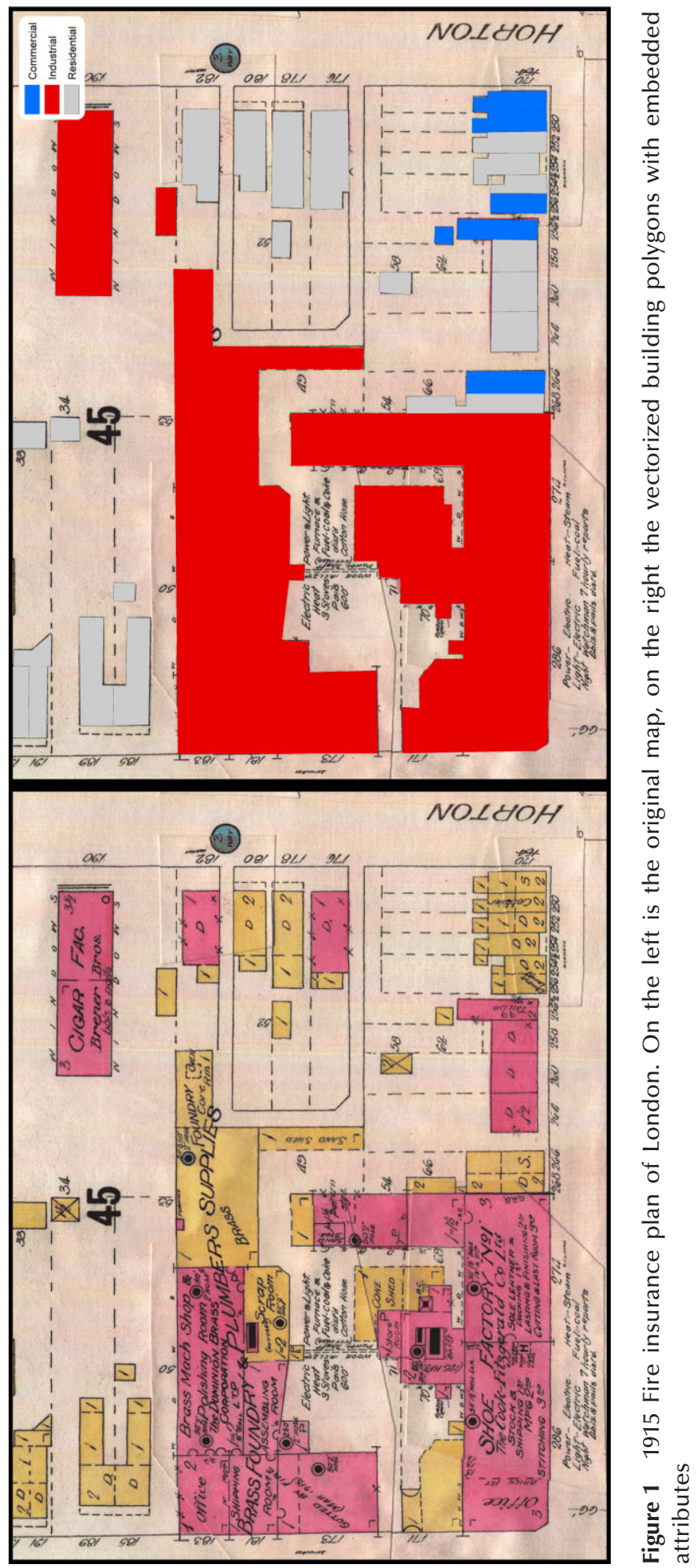


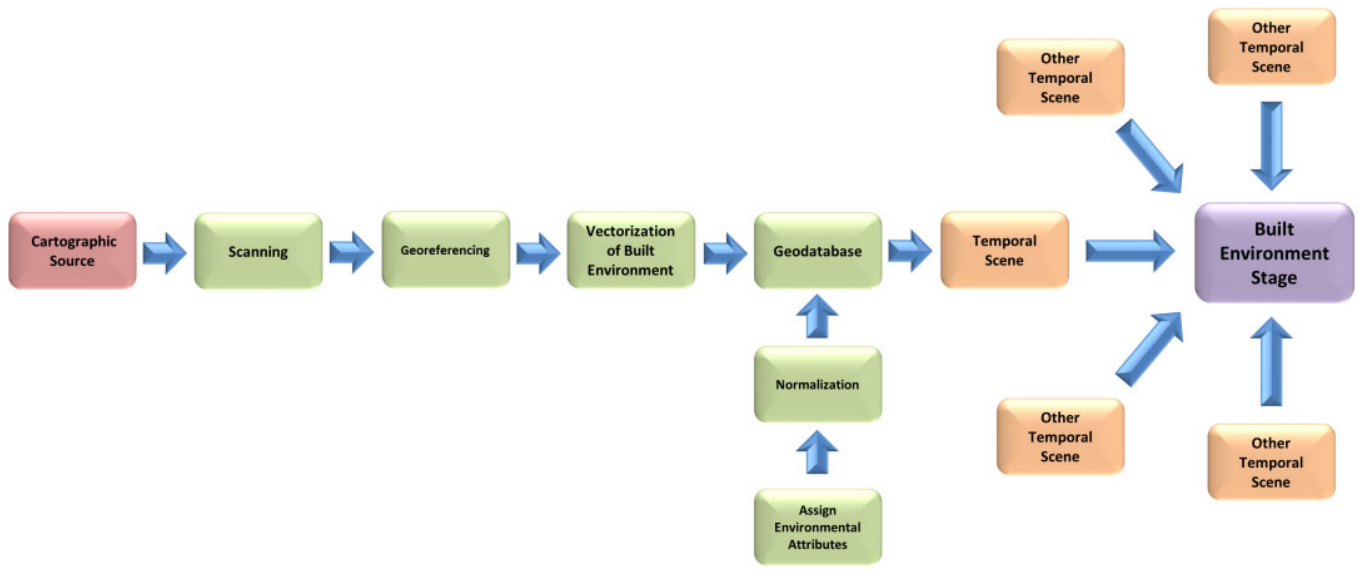

Figure 2 Built environment stage workflow

each feature in the geodatabase. To facilitate comparison across multiple temporal periods, the variables needed to be normalized using common categories. Once loaded into the geodatabase, the temporal scene was complete and ready to be added to other scenes in the built environment stage of the HGIS.

Of equal importance to the creation of a contextually rich stage-based historical GIS is the civic addressing that is found within the FIPs. Each property is noted with a precise civic address that can be used as a common spatial identifier, facilitating an easy integration of a wide range of sources into the GIS. Of particular interest to Canadian scholars is how this addressing can be used to facilitate the geocoding of the decennial census of Canada prior to 1901, when no addresses are listed in the manuscript records. This would also be of interest to other scholars who have access to individual-level data devoid of a fine-grained spatial identifier.

\subsection{The Social Environment Stage}

A social environment stage can be created using any combination of sources that, when record linked, provide a rich dataset outlining the many social indicators found in the geographic area of interest. Annual city directories and the decennial census of Canada are the cornerstones of our social environment stage. We elected to use the decennial census as it provides the most reliable record of 19th and early 20th century urban populations (Curtis 2001; Sager and Baskerville 2007; Olson and Thornton 2011).

We wanted to have as rich a social environment stage as possible. The combination of decennial censuses and annual city directories provides not only the name, age, occupation, birthplace, ethnicity, and marital status of each individual, but also the relationships found within each family unit or domicile, the tenancy of each residential unit, and the place of work for those employed both within and outside the home. We have benefited from the valiant efforts of the Canadian Century Research Infrastructure Project (Gaffield 2007), the 1881 Canadian Census Project (Dillon 2000) and the Historical Data Unit at the University of Guelph, who have each assisted in the creation of a complete count of the entire population of the city of London from 1871-1901. This has allowed us to map every individual to their exact residential unit, including children, a population that is rarely captured in 


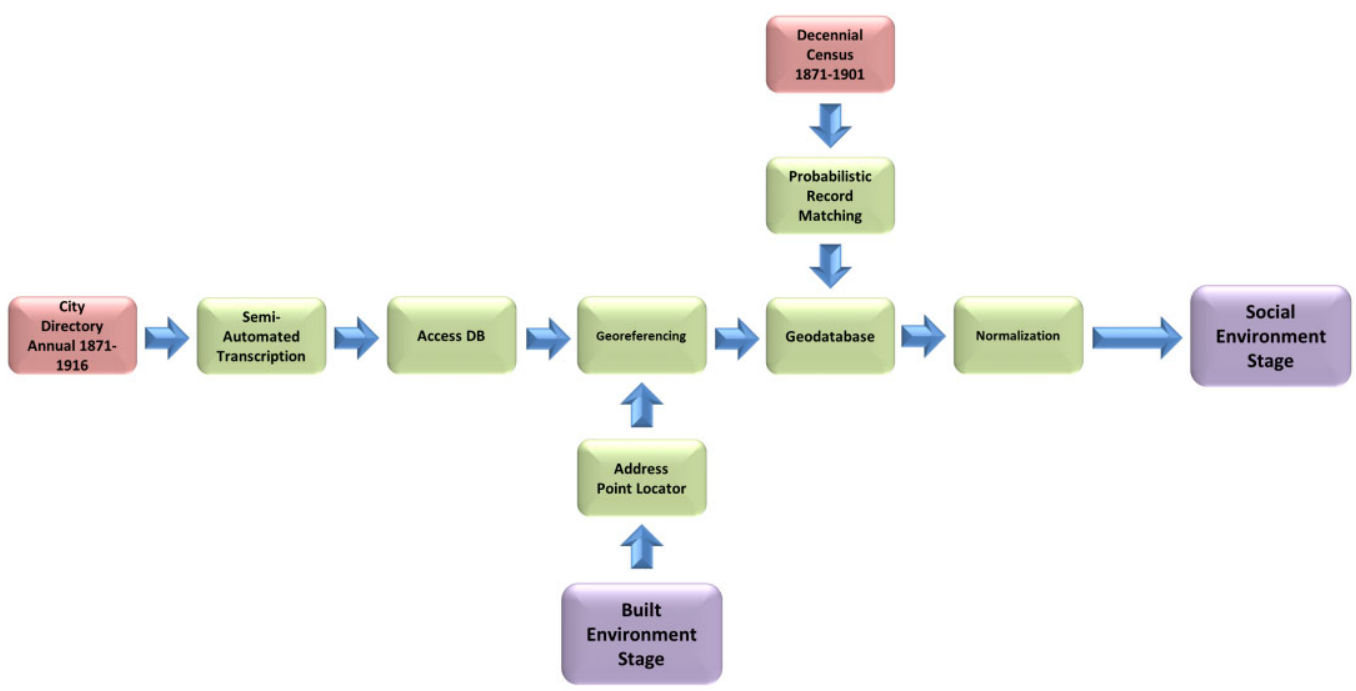

Figure 3 Social environment stage workflow

geo-demographic studies. The city directories, geocoded on an annual basis, allow us to understand the social environment between the census years, including residential mobility, changing social mobility, and property ownership. We can even follow as domestic scenes change, such as when teenagers leave their parents' homes to start their own households.

A historical city directory typically consists of four sections. There is an alphabetical listing of each resident in the city, which includes their full name, residential address, housing tenure, occupation, and workplace. A business directory lists all commercial and industrial operations in the city. It is sorted by the primary service provided or good produced, and includes the name, full address, and in some cases the owner and/or partners of the business. A street directory provides a detailed geographical record of each street. Every address in the city is recorded along with the head of household or business located at that address. Each address is placed in order as if you were walking down the street and notations of proximity to cross streets and vacant land are included. Finally, the miscellaneous directory lists the churches, schools, post offices, and other similar public buildings located throughout the city.

The creation of the social environment stage began with the semi-automated transcription of the city directories (Figure 3). All four sections of the directory, for every year between 1871 and 1901, were run through an optical character recognition (OCR) procedure in Adobe Acrobat. The OCR is imperfect, so each record was reviewed by a researcher who made corrections or manual transcriptions where needed. The file was then text parsed and imported into a MS Access database. Using the temporally corresponding built environment stage, we created an address point locator and geocoded the directories. This overcame most issues associated with geocoding historical records, such as street name changes or additions, and changes in residential buildings and lots. Seventy-one percent of the city directory entries across all years were geocoded through the automated functions within ArcGIS. A combination of factors prevented the remainder from being completed with the point locator. In 18711883 , some addresses were indicated with street intersections or by vernacular names given to major commercial buildings such as "Union Block" or "Albion Buildings"; these entries were 
manually geocoded. Entries for boarders or hotel dwellers often included the name of the owner of the lodging place rather than an address; these entries were researched further and manually georeferenced. The final geocoding capture rate was $97.2 \%$ of city directory entries across all years, with the lowest single year (1879) being $94 \%$.

To facilitate the georeferencing of the decennial censuses of 1871, 1881, and 1891 (which provide a geographic reference to a district but no civic addresses), we used a customized version of LinkageWiz, a probabilistic record matching software, to record link the census to the city directory of the same year (LinkageWiz 2011). The records were blocked using enumeration areas and last names. Last names were blocked with various phonetic algorithms and string comparisons applied. Matching was then performed using match weights for first name, gender (derived from a lookup table of first names), and occupation. Occupation also included a lookup table of similar occupational titles derived from the Historical International Standard Classification of Occupations (HISCO) (van Leeuwen et al. 2002, 2004). Only the most probable matches (90\% threshold) were automatically matched; the remainder were manually reviewed by the researchers before inclusion in the geodatabase.

Historical demographers are acutely aware of the issues that have resulted from the change in the census questions from enumeration to enumeration. The final step in the creation of the social environment stage included our attempts to normalize the census and directory variables for easier comparisons year over year (see Figure 4 for the variables found within the social environment stage geodatabase). We have largely followed the lead of the researchers involved in the North Atlantic Population Project (NAPP) (Ruggles 2002; Roberts et al. 2003). Relevant variables such as the number of rooms and state of construction found within the 1891 census were extracted and included in the built environment stage.

The result is a robust geodatabase, or social stage, that affords us a completely new way of looking at a city and its population. For the better part of the twentieth century, researchers have followed the model of the Chicago School of Sociology, studying urban populations by placing them within the arbitrary boundaries and hard edges of the census tracts. Much like the pioneers Charles Booth (1889) and Herbert Ames (1897), we can now map and analyze social patterns at the scale of a single block. We can see that a new Irish Catholic immigrant, his wife, and eight children live in the back lot behind an English Protestant industrial capitalist who employs three servants. At an even finer scale, we can see the merchants' wives who may share a friendly salutation from porch to porch and the young single factory worker who rents a room above the living quarters of a bourgeois insurance agent. A myriad of possible research topics may be interrogated in a social environment stage built at this micro-scale. Rich individual-level data allows a researcher to ask questions and discern patterns that are lost in aggregated census data.

Researchers also benefit from the flexibility and adaptability of having a GIS built upon a set of two or more spatially-linked, multi-temporal stages. The system can combine any range of data included within the stages' geodatabases, and additional "bricks" may be added to the foundation of the GIS as new research questions arise. We found ourselves doing so as we moved from projects focused on urban morphology to those more demographic in nature.

We can combine the spatial accuracy of civic addresses with the cartographic record of businesses, buildings and lots found on the FIP to map nearly any archival source with the most subtle reference to an individual, business, event, or street corner. This allows the unique opportunity to incorporate into the HGIS seemingly aspatial archival sources such as payroll records, newspapers, or police digests, with all people and events placed in their exact historic 


\begin{tabular}{|c|c|}
\hline LAST_NAME & Last Name of Individual \\
\hline FIRST_NAME & First Name of Individual \\
\hline INITIAL & Middle Initial of Individual \\
\hline OCCUPATION & Occupation \\
\hline WORKADD & Workplace Address \\
\hline WORKPLACE & Workplace Name \\
\hline TENURE* & Home ownership or renter \\
\hline STREETNUM & Street Number \\
\hline STREETNAME & Street Name \\
\hline SUBURB* & Suburb if applicable \\
\hline BUILDING & Name of building residence is located within, if applicable \\
\hline HOTEL & Name of hotel resident is living in, if applicable \\
\hline WORK_ID & Unique ID linking to business directory extry for place of work \\
\hline WARD & Municipal Ward \\
\hline CENSUS_ID & Unique ID created during census manuscript transcription \\
\hline FAMILY_ID & Unique ID for each family in census \\
\hline INST & Type of instiution resident resides in, if applicable \\
\hline DwSize & Number of persons in the dwelling \\
\hline Fsize & Number of persons in the family unit \\
\hline NAMELAST & Last Name of Individual \\
\hline NAMEFIRST & First Name of Individual \\
\hline SEX* & Gender \\
\hline AGE* & Age \\
\hline MARST* & Marital Status \\
\hline RELATE* & Relationship of Individual to Household Head \\
\hline BPL* & Birthplace \\
\hline FBPL* & Father's Birthplace \\
\hline MBPL* & Mother's Birthplace \\
\hline RELIGION* & Religion \\
\hline OCC* & Occupation \\
\hline EMPLOYER & Indicates if the individual was an employer \\
\hline WageEarner & Indicates if the individual was a wage earner \\
\hline UNEMP & Indicates if the individual was unemployed \\
\hline EMPHANDS & Indicates the average \# of people employed by the individual during the year \\
\hline CANREAD & Indicates if the individual can read \\
\hline CANWRITE & Indicates if the individual is can write \\
\hline BLIND & Indicates if the individual is blind \\
\hline DEAF & Indicates if the individual is deaf \\
\hline UNSOUND & Indicates if the individual had an unsound mind \\
\hline REL_STAT & Normalized field for Religion \\
\hline SEX_STAT & Normalized field for Gender \\
\hline AGE_STAT & Normalized field for Age \\
\hline BPlacesTAT & Normalized field for Birthplace \\
\hline EthnicSTAT & Normalized field for Ethincity- derived from Father's and Mother's birthpla \\
\hline MARST_STAT & Normalized field for Marital Status \\
\hline OCC_STAT & Normalized field for Occupation \\
\hline Wk_STAT & Normalized field for whether workplace is known \\
\hline NapHisco & Normalized field for NAPP-modified HISCO Code \\
\hline OccClass & Normalized field for Occupational Social Class \\
\hline $\mathrm{NapHisOcc}$ & Normalized field for HISCO-derived Occupational Title \\
\hline
\end{tabular}

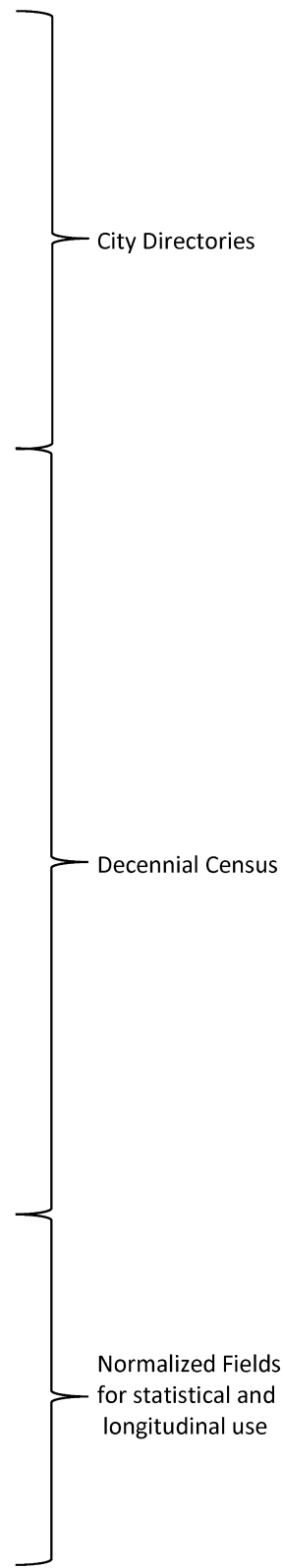

Figure 4 Example of variables included in the 1891 social environment stage geodatabase. The * indicates the presence of a corresponding numeric variable to facilitate statistical analysis

spatial locations. Researchers thereby have a novel perspective on the past, allowing us to pose new questions and guiding us toward more robust answers. This also allows for a deeper contextualization of sources, as each source can be viewed within its appropriate temporal scene as well as in its spatial relation to other actors or events. 


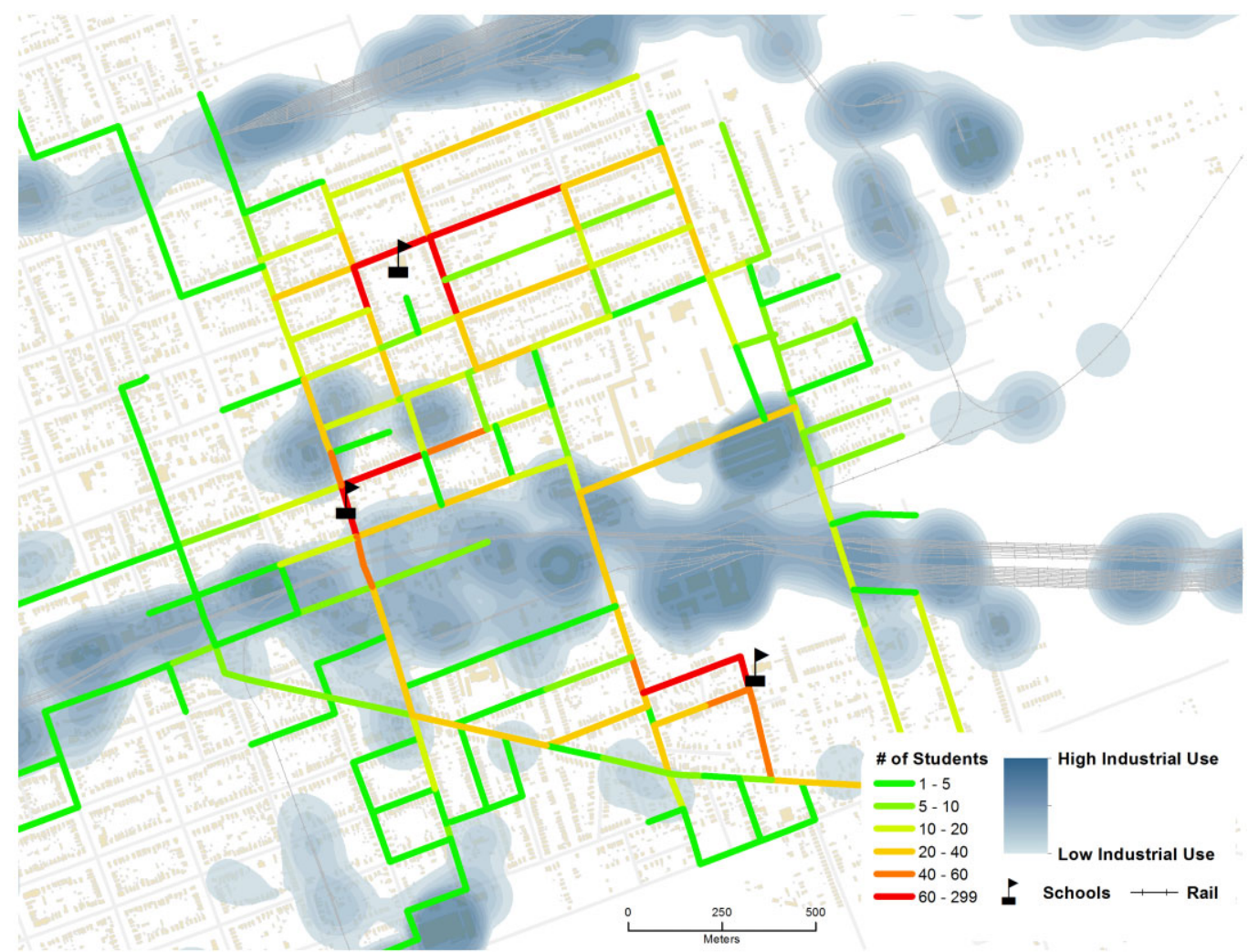

Figure 5 Built and Social Environment Stages used together to explore children's potential exposure to noxious industrial environments on their journey to school

To illustrate, we have harnessed the built and social environment stages to explore the potential exposures to noxious industrial environments during children's daily journey to school in the 1880s (see Figure 5). We record-linked to the social environment stage an attendance register of pupils that enumerated all of the students $(n=699)$ from the three primary schools in the suburban town of London East. The register only included each student's name, age, parent's name, and daily attendance at school. The demographic robustness of the social environment stage allowed us to locate these children through their parents and place them within their homes. Using the road and pathway network in the built environment stage, we calculated their likely journeys to school using a shortest path analysis. The routes are aggregated in Figure 5 to illustrate the number of children who traveled on any given street segment in a day. By calculating a weighted interpolation of the square footage of each industrial building and railyard, we created a surface that represents the industrial areas of the city and juxtaposed it with the journeys to school. We see that over half of the students $(\mathrm{n}=354)$ were traversing an industrial area, representing on average $371 \mathrm{~m}$ of their journey and approximately five minutes of walking time, depending on the age of the student (see Figure 6). Further analysis with the social environment stage shows us that children of semi-skilled or unskilled workers had the least exposure and children of parents in professional occupations had the most. This pattern is likely a reflection of the difference in housing patterns of the industrial suburb, with lower 


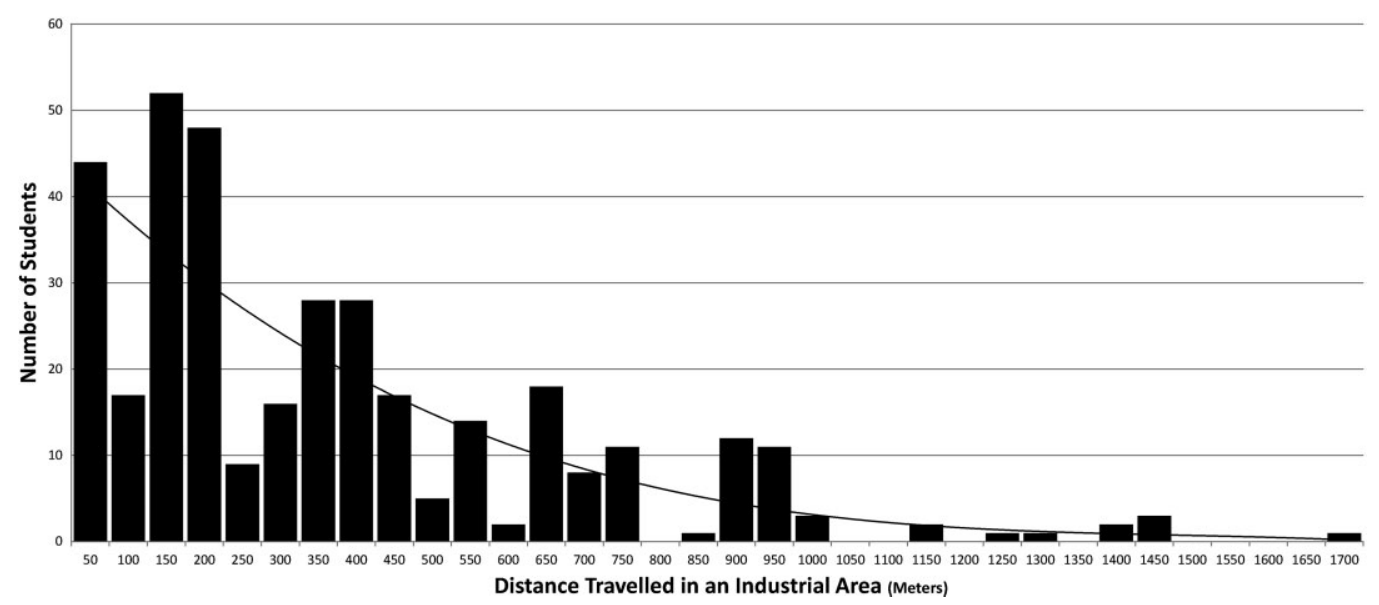

Figure 6 Distances travelled within an industrial area by children on their daily journey to school

cost housing nearer to the core, and thus the school, and more elaborate housing built at the city's fringe. This short example illustrates how the contextualization of historical sources within a stage-based GIS can lead to new perspectives - in this case, on the 19th century time-space paths of children and the environments they traversed on a daily basis.

\section{Integrating and Contextualizing Narratives}

Our interest in spatializing narratives stems from a larger research program that explores the social structures of 19 th century cities through the lens of spatial mobilities. We wish to understand the true impact of segregation on the creation of community by looking at the extent of social interaction through the re-creation of individual space-time paths, what we call the spatial stories of urban life. We quickly determined that the best sources of such fine resolution data on social interaction are personal diaries. Nineteenth-century personal diaries vary widely in the type of information that was recorded in them. Culley (1989, pp. 15-17) outlines that most diaries served not only as a method of private personal record keeping (i.e. personal finances, illness, and appointments) but also as semi-public records of life. Culley, as well as Adams and Gossage (1998), argue that men wrote about their public activities and women about family and community events. Our experience with urban diaries confirms this.

\subsection{Digitalization and Text Parsing}

To date, we have incorporated 12 diaries that have overlapping spatial and temporal extents. The diaries were located in a regional archive and first had to be digitalized in preparation for inclusion in the GIS. The diaries were scanned page by page and transcribed manually. Attempts were then made to parse the text using a number of automated text mining methods including natural language processing (Piotrowski 2012), named entity recognition (Nissim et al. 2004), and feature selection algorithms. We had limited success; even with the use of disambiguation techniques, we found that less than $40 \%$ of the text was able to be identified satisfactorily. A host of reasons influenced this low capture rate, such as the wide use of 


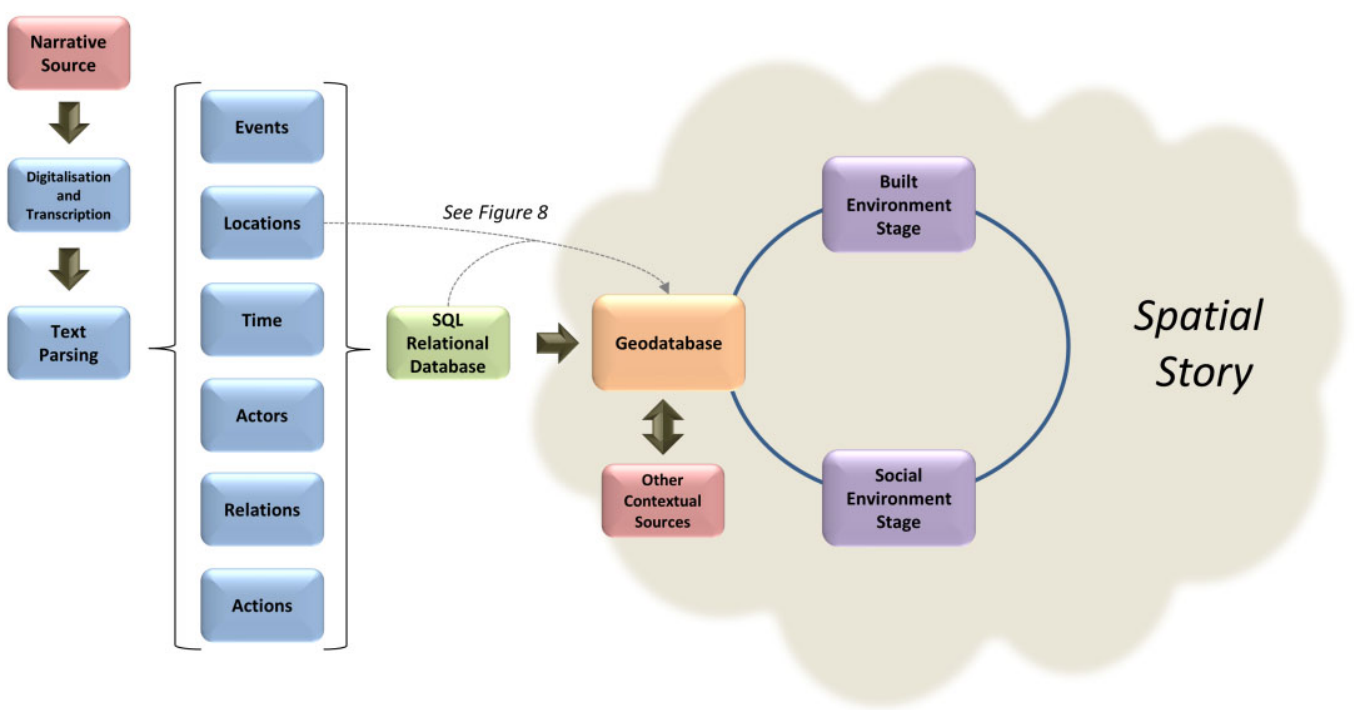

Figure 7 Workflow to integrate and contextualize qualitative sources in a GIS. The example is a written narrative. This method allows us to create a rich spatial story of a given time and place

shorthand, nicknames and archaic terms. Foremost was the heavy use of vernacular terms used for locations or events. For example, "went to 7'oclock (sic) prayer meeting at the sabbath school" or "met at the gallery building before heading to tea at Old J Weston's."

Automated text segmentation and event generation is an area of significant interest to computational linguists who are intrigued by the challenge as well as the research possibilities available if we could harness the vast archive of data stored in texts, especially the limitless textual archive of the Internet. Interest in historical texts has been limited until very recently. Notable efforts are underway by Michael Piotrowski (2012) to tackle the challenges of applying current natural language processing techniques to historical corpora. Further work has begun by Ian Gregory and others as part of a larger project in the spatial humanities (Gregory 2013). Despite these recent efforts, no universally applicable technique for parsing and identifying historical texts is currently available. Piotrowski (2012, p.100) argues that most successful natural language processing projects for historical texts have taken place with tools built specifically for a historical corpora representing a specific time and place. We did not have the resources to create a tool specific to our corpora and thus found it more effective to parse the text manually.

\subsection{Creating Events from Texts}

A primary concern among qualitative social scientists is how to maintain the important contextual clues about the people, places, and events that are embedded within a written narrative. The benefit of a manual approach to text parsing when combined with a stage-based GIS is the ability to tease out not only subtle or incomplete references to people, places, and events, but also to extrapolate time, relationships, and spatial mobilities.

We started by first parsing out unique socio-spatial events (Figure 7). An event can take two forms. First, it can be a temporally specific mention of someone who was spatially mobile. 
This can be obvious, such as "left for work at 7am", or more subtle, such as "We had dinner \& supper at 438" (438 is the address of the diarist's in-laws, thus we can infer movement). The second type of event is one that involves a social interaction, even if we are unsure of the extent of the spatial mobility present. For example, "last evening Dick was with us for tea". We do not necessarily know where tea took place but we are still able to parse out this interaction.

Locations were then extracted in a similar manner; the details of this process are outlined in Section 5. Time was recorded for each event at the finest resolution possible (both absolute and deictic) in addition to where an event fitted into the sequence of socio-spatial events in any given day. This notation in the relational database is needed for the re-creation of spatial stories. A record of all actors, or people recorded in the diary, complete with their full geodemographic record from the social environment stage, was created. The relationships between each actor and the diary writer, as well as the relationships between all actors to each other, were extracted from the diary. We also used the various temporal scenes available in the social environment stage to create a web of social relations beyond what is immediately obvious from the diary (Figure 7). We can thus see not only familial branches but also economic, social, political and employment-based relations. In essence, we have captured a comprehensive social network of the entire city, centered on individual diary writers.

Actions were the final element of our relational database to be parsed out of the narrative. Actions include a number of elements such as the direction of travel, origins, destinations, and waypoints, or stops along the way. Each event was codified using an index of "why" codes to indicate whether it was work-related, social, educational, religious, for commerce, or otherwise; multiple reasons could be indicated. Finally, the complete passage from the digitalized narrative was included so researchers can view the original event in context.

\section{Georeferencing Qualitative Sources}

The spatialization of historical sources is still in relative infancy. Most projects georeference historical sources using modern spatial datasets and address locators, as the time and resources needed to create temporally-specific geolocators is enormous. Notable exceptions include the pioneering project Montréal l'avenir du passé Gilliland and Olson 2003). Others include the recent efforts of the Urban Transition Historical GIS Project (Logan et al. 2011), which has successfully geocoded the 1880 US census to a resolution as fine as the street segment, and the historical GISes of Alexandria, Virginia and Newport, Kentucky created by Debats (2009). Another approach advocated by Southall et al. (2011) has been to utilize databases of historical place names and digital gazetteers. Their methods have made the geocoding of locations somewhat less taxing; however, they do not serve to map qualitative spatial relations at the scale of everyday life, such as the location of the "coloured barber near the market". Our interest in qualitative sources, including their incomplete spatial references, demanded the creation of the stage-based GIS outlined here. We see this as the most complete gazetteer available for a single city, where we are able to map every subtle event or mention of a person or place with relative ease.

The location fields that are parsed out of a narrative source represent not only locales directly or indirectly mentioned by the diary writer, but also any spatial references that can be inferred by the actions, events, or actors mentioned in the diary. That is, every actor's actual location at a specific time is georeferenced, as well as their home location, workplace, and any other locations available through the built and social environment stages. The source-based 


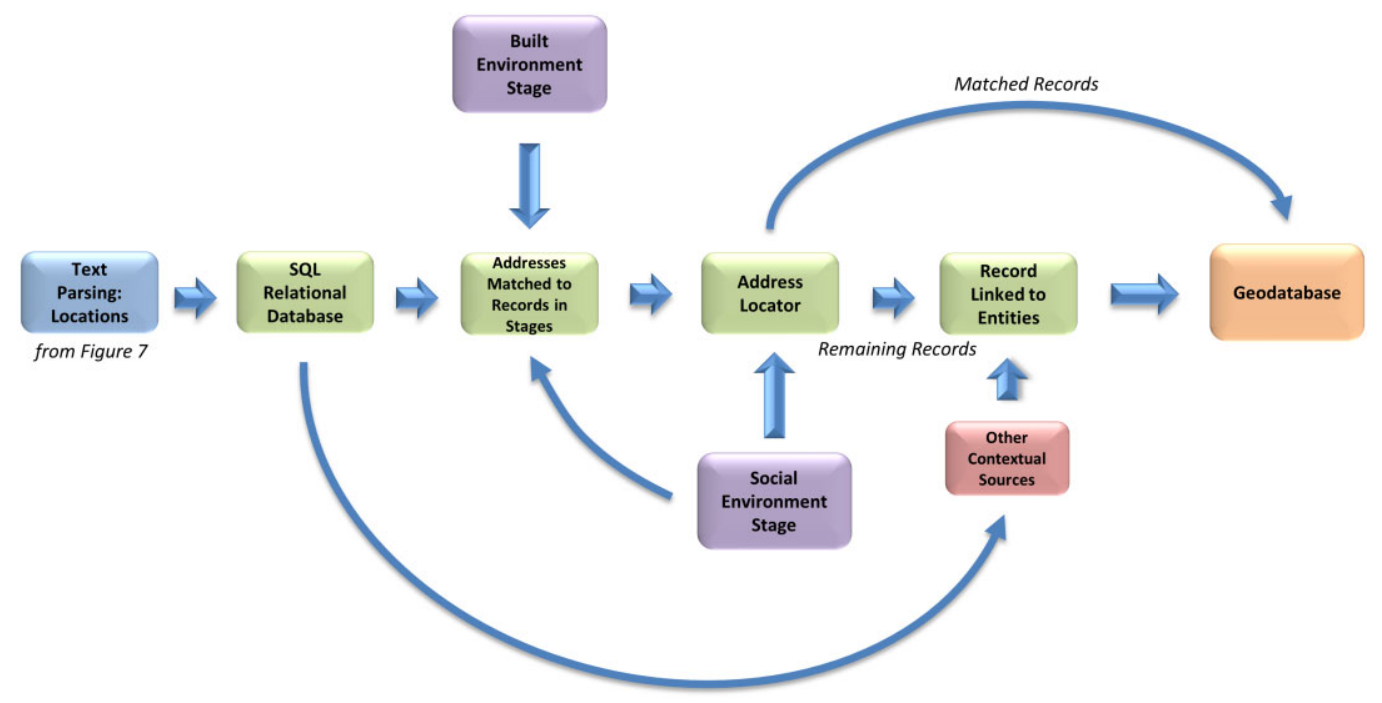

Figure 8 Georeferencing workflow for narrative sources

contextualization also allows a researcher to map locations that are not absolute, such as the extent of what individuals refer to as "downtown", or the scale of a neighborhood as seen through the eyes of the writer.

The georeferencing of narrative sources is a semi-automated procedure. It begins by running the parsed location attributes from the written narrative through an automated record linking procedure to records found within both the built and social environment stages. The record link may include a partial civic address or may be a link to a name, business, or building. The civic address, as discerned from the stages, is then added to the record in the relational database (Figure 8). The address-linked records are geocoded using the address locator created during the construction of the social environment stage. Successfully geocoded records are then added to a new geodatabase. The remaining records are reviewed manually and linked to multiple entities in both the relational database and other contextual sources in the HGIS that may provide spatial references.

The ability to contextualize the sources within a large spatially and temporally referenced database is vital to being able to precisely georeference a narrative source. One of the diaries included within our larger project is that of Richard Matthews. Matthews' diary spans 36 years, 1863-1899. We have thus far focused on two years of his life, 1881-1882, when he was a married father of six and a clerk at the city's post office. Nearly 1,000 events involving just under 200 actors in 269 unique locations were geocoded from his diary using this methodology. Table 1 outlines the results of the geocoding procedure by each intermediary step. For both events and actors, only $2 \%$ of entries could be geocoded using the addresses written directly in the diary. However, once the entries were record linked to addresses captured in the two stages, we were able to geocode $90 \%$ of the events and $70 \%$ of the actors parsed out of Matthews' diary.

Some record links were direct 1 -to-1 matches of an actor's name to their corresponding entry in the social environment stage, while others were matched through a combination of multiple variables. For example, we return to the case of the "coloured barber near the market" that Matthews mentions visiting in the spring of 1882. Using the built environment 
Table 1 Number of actors and events mapped by geocoding procedure

\begin{tabular}{lllllll}
\hline & $\begin{array}{l}\text { Number } \\
\text { of events/ } \\
\text { actors }\end{array}$ & $\begin{array}{l}\text { Using } \\
\text { address found } \\
\text { in diary* }\end{array}$ & $\begin{array}{l}\text { Using address } \\
\text { captured } \\
\text { from stages }\end{array}$ & $\begin{array}{l}\text { Contextual } \\
\text { manual } \\
\text { geocodes }\end{array}$ & $\begin{array}{l}\text { Not } \\
\text { mapped }^{* *}\end{array}$ & $\begin{array}{l}\text { Final } \\
\text { geocode } \\
\text { rate }\end{array}$ \\
\hline Events & 927 & 19 & 786 & 30 & 92 & $90 \%$ \\
Actors & 192 & 4 & 125 & 5 & 58 & $70 \%$ \\
\hline
\end{tabular}

* Diary of Richard Matthews, 1882

** 27 of the not mapped actors were family, preachers, or politicians who reside outside of London

stage, we can perform a simple spatial buffer of a short walking distance around the market. Then, within the buffer, we can perform a SQL query for Occupation = Barber AND Ethnicity = African within the social environment stage. The result is the discovery of Matthews' barber as a single, recently immigrated, 30-year-old American man named William Berry. He operates his business on the first floor of a rented shop at 10 Market Lane, just steps away from the market square. From here, other contextual sources could be referenced, such as Matthews' financial record books to see how much he paid for a haircut, or newspapers for advertisements or stories about the barber shop.

As an example of what is possible, Figure 9 outlines the spatial distribution of actors in Matthews' diary contextualized within the two environmental stages. We have included land use characteristics from the built environment stage as it provides a clear image of the delineated spaces in the city. Using a simplified version of the Darroch and Ornstein (1980) occupational class scheme we aggregated the actors in Matthews diary into one of three social classes. The result is a spatial view of the diversity of individuals Matthews interacts with throughout his daily life. No one social class dominates and we see that actors live in a range of residential situations from single unit detached homes in the suburbs, to small bungalows and residential hotels in the industrial areas of the city. We see relations in both in the wealthy Woodfield district north-east of downtown and in the working class London East neighborhood. These are patterns that would not be possible to discern without the ability to place the narrative within the context of the rich built and social environment stages.

\section{Towards Spatial Stories: The Case of Richard Matthews}

Utilizing a stage-based GIS provides not just the ability to georeference qualitative locations but also the ability to recreate the space-time paths and the ensuing social interactions that are otherwise hidden within qualitative sources. A simple comment about getting a haircut deepens our understanding of activity spaces and the distances urban residents would travel in the walking city to complete their personal and household chores. It provides us a taste of how racial differences were experienced during the day when residents left their segregated neighborhoods. It may be a launching point for enquiries into the economic opportunities and experiences of new immigrants. We recognize that no single case will lead a researcher to in-depth conclusions, but this simple example, grouped with thousands of others, provides the script for the creation of a rich spatial story. 


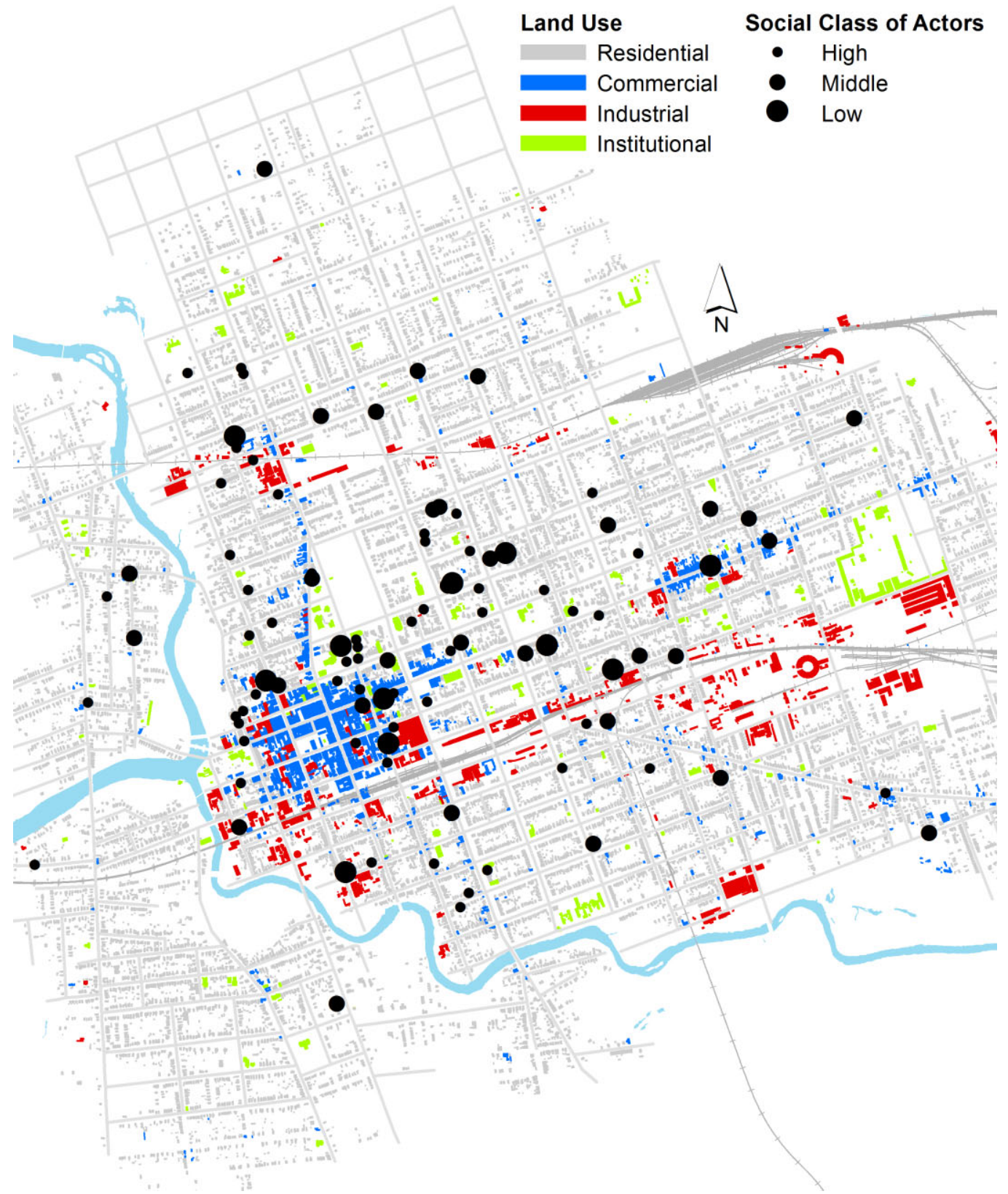

Figure 9 Built and social environments used to spatialize Actors in Richard Matthews' diary

Our current research interests are focused on developing a better understanding of the impact of diurnal segregation (or integration) on the everyday lives of individuals, both past and present. Who Matthews does and does not visit on his weekly Sunday stroll provides only a limited view of the social structures impacting his life. Utilizing the two environmental stages and the 12 diaries, we have recreated the time-space paths of Matthews, as well as hundreds of 
other urban residents, for various time periods between 1881 and 1901 . These spatial stories shed light on the true social distances that influenced the lived experiences of residents as they traversed the city to work, school, church, and play.

Time geography and time space modeling has a deep scholarship. Inspired by the pioneering work of Hägerstrand (1970) on space-time paths and prisms, scholars continue to work towards effective geovisualization techniques that overcome the interpretive difficulties of three dimensional geographic data (Kwan and Lee 2004; Nakaya 2013; Yu and Shaw 2011). While others are developing new models that can be used to interrogate spatio-temporal mobility data (Chen et al. 2011; Shaw and Yu 2009; Stewart et al. 2013; Yu 2006). However, with only one notable exception (Mennis et al. 2013), the space-time patterns observed are not placed within a rich, multi-variant environmental framework like what we present here.

Our approach to the geovisualization and analysis of spatial stories is to immerse the narrative source within a three-dimensional model of the city created using the two stages described above. Using the 3D capabilities of ESRI's ArcScene 10, we have created a "Google Street View-like" representation of the city. Figure 10 represents a recreation of the morning journey to work for Richard Matthews on April 12, 1882 as he described it in his diary. His time-space pattern is highlighted by the brown arrow that shows his departure at 8:15am and his arrival 10 minutes later at Fred Wheeler's home to borrow a copy of David Copperfield. He continues on to work, arriving at 8:50am. This rather routine journey to work becomes a spatial story when we not only contextualize the interaction between the actors in time-space, but set the route within the larger environment that influences how the space is used and experienced. Here we have utilized the social environment stage to symbolize each building polygon from the built environment stage by ethnicity of the head of household. Labeled atop each polygon is the value of each property in dollars per square meter as derived from the total building value found in the municipal tax roll. Vegetation, telegraph poles, and gas street lamps are included; their locations were identified using period photographs and a later geodetic survey which mapped individual trees. Photographs of buildings are available through hyperlinks embedded within the built environment stage. Thumbnails are provided below the scene and change as you modify the extent of the map. Many other built and social environment variables are available to be viewed and analyzed by the researcher but the limitations of a paper map restrict us from illustrating them here. Through this $3 \mathrm{D}$ representation, we have an enlightening view of the physical and social landscapes actors experienced and interacted with in their daily space-time rhythms.

\section{Conclusions}

This article has outlined a new conceptual framework and methodology for the study of urban environments. Whether the enquiry is the influence of the built environment on personal mobility or the relationship between residential tenure and social segregation, it is critical to set the scenes upon a spatially and temporally accurate representation of the spaces studied. To accomplish this, we argue for moving beyond the use of generalized geospatial platforms such as Google Earth, or the use of census tracts or similar aggregated units. By operating at the scale of the individual, be it buildings or actors, we can not only overcome the modifiable areal unit problem, but we can perform multi-scaled analysis and aggregation that cannot otherwise be accomplished. This approach makes possible, for the first time, the realization of the promise that draws many scholars to GIS - that by "assigning a geographic reference to data. . it then becomes possible to compare that characteristic, event, phenomenon, etc. with 


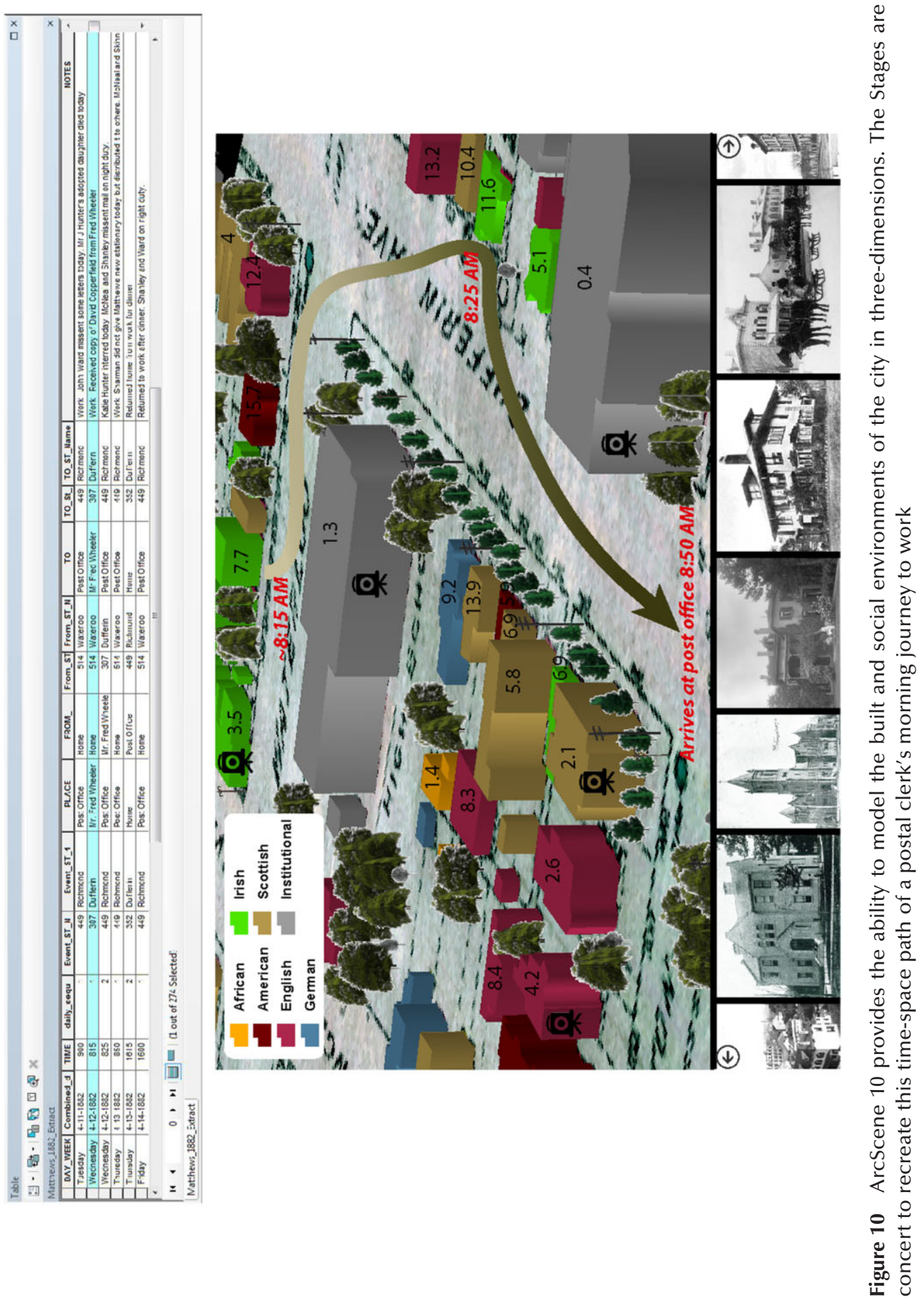


others that exist in the same geographic space. What were previously seemingly unrelated facts become integrated and correlated." (Kemp 2010, p. 32)

This article has also provided a methodology for the re-creation of individual space-time paths using narrative sources within a stage-based GIS. Core to this approach is the ability to parse narrative sources into six parts, each reflecting either a spatial, temporal, or social relationship found within the narrative. Then, using temporally-specific attributes from the built and social environment stages, we georeference the narrative to the exact locations noted within the urban fabric. Although we preserve access to the original narrative via a hyperlink in the attribute table, we recognize that by segmenting the narrative in this way, much of the qualitative nature of the source is lost. We see this as a small price to pay for the new perspectives that can be seen when you integrate a narrative within the stage-based GIS. By harnessing the spatial precision, analytical capabilities, and contextual cues available through the stagebased GIS, researchers can now better understand the role that environmental interactions play on the quantity and nature of human daily mobility. This is approach is congruous with Kwan's (2013) call for a temporally-integrated approach to the study of social geographies.

Further, this article has outlined the need to place both the source data and the space-time patterns observed within their larger environmental contexts. We advocate for the creation of a "full city view" or "real world" within a geospatial environment; however, as Black (2010 p. 467) reminds us, "the past can never be recovered as a solid whole, as history is always fragmented". We must acknowledge that when working with any historical sources there are inherent inaccuracies, biases, and omissions, thus limiting the assumptions and potentially the analysis one can perform. Additionally, we face many of the challenges outlined by Elwood (2009a) such as how to manipulate and represent such complex data and how to overcome the heterogeneity that is intrinsic to such representations. We also recognize some of the limitations that Sheppard $(1995 ; 2005)$ outlines when attempting to represent qualitative information in the Boolean logic and map algebra of the raster and vector GIS.

Although our case study uses historical sources, we see these approaches as being applicable to a wide range of contemporary lines of enquiry. Scholarship ranging from impact of the built environment on individual health to how complex social structures influence the settlement patterns of new immigrants can benefit from this approach. Although a significant investment of time and resources is needed to build a stage-based GIS, we see the rewards to be great. The diversity of enquiries that is possible is limited only by the imagination of the researcher.

\section{References}

Adams A and Gossage P 1998 Chez Fadette: Girlhood, family, and private space in late-nineteenth century Saint-Hyacinthe. Urban History Review 26: 56-68

Aldred D A and Wang J 2011 A method for obtaining and applying classification parameters in object-based urban rooftop extraction from VHR multispectral images. International Journal of Remote Sensing 32: 2811-23

Ames H 1897 The City Below the Hill: A Sociological Study of a Portion of the City of Montreal. Montreal, QC, Bishop Engraving and Printing Company

Berman M L 2004 Key Issues in Compiling a Digital Gazetteer for China's Historical Religious Sites. Berkeley, CA, ECAI Congress on Cultural Atlases

Black I 2010 Analysing historical and archival sources. In Clifford N, French S, and Valentine G (eds) Key Methods in Geography (Second Edition). London, Sage: 466-84

Bloomfield G T 1982 Canadian fire insurance plans and industrial archeology. Journal of the Society for Industrial Archeology 8: 67-80 
Bodenhamer D, Corrigan J, and Harris T (eds) 2010 The Spatial Humanities: GIS and the Future of Humanities Scholarship. Bloomington, IN, Indiana University Press

Bol P 2008 Creating a GIS for the history of China. In Knowles A K (ed) Placing History: How Maps, Spatial Data, and GIS are Changing Historical Scholarship. Redlands, CA, Esri Press: 27-59

Booth C 1889 Life and Labour of the People. London, Macmillan

Carneiro C, Morello E, Voegtle T, and Golay F 2010 Digital urban morphometrics: Automatic extraction and assessment of morphological properties of buildings. Transactions in GIS 14: 497-531

Chen J, Shaw S, Yu H, Lu F, Chai Y, and Jia Q 2011 Exploratory data analysis of activity diary data: A spacetime GIS approach. Journal of Transport Geography 19: 394-404

Cooper D and Gregory I 2011 Mapping the English Lake District: a literary GIS. Transactions of the Institute of British Geographers 36: 89-108

Corbett J and Rambaldi G 2009 Geographic information technologies, local knowledge, and change. In Cope M and Elwood S (eds) Qualitative GIS: A Mixed Methods Approach. London, Sage Publications: 75-91

Cowan D, McGarry F, Moran H, McCarthy D, and King C 2012 Dreamcatcher: IT to support indigenous people. IT Professional 14: 39-47

Craig W, Harris T, and Weiner D (eds) 2002 Community Participation and Geographic Information Systems. New York, Taylor and Francis

Culley M 1989 "I look at me": Self as subject in the diaries of American women. Women's Studies Quarterly 17: 15-22

Curtis B 2001 The Politics of Population: State Formation, Statistics, and the Census of Canada, 1840-1875. Toronto, ON, University of Toronto Press

Darroch G and Ornstein M 1980 Ethnicity and occupational structure in Canada in 1871: The vertical mosaic in historical perspective. Canadian Historical Review 61: 305-33

De Moor M and Wiedemann T 2001 Reconstructing territorial units and hierarchies: A Belgian example. International Journal of Humanities and Arts Computing 13: 71-98

Dear M, Ketchum J, Luria S, and Richardson D (eds) 2011 GeoHumanities: Art, History, Text at the Edge of Place. London, Routledge

Debats D 2008 A tale of two cities: Using tax records to develop GIS files for mapping and understanding nineteenth-century U.S cities. Historical Methods 41: 17-38

Debats D 2009 Using GIS and individual-level data for whole communities: A path toward the reconciliation of political and social history. Social Science Computer Review 27: 313-30

Dennis S, Gaulocher S, Carpiano R, and Brown D 2009 Participatory photo mapping (PPM): Exploring an integrated method for health and place research with young people. Health and Place 15: 466-73

Dillon L 2000 International partners, local volunteers, and lots of data: The 1881 Canadian Census project. International Journal of Humanities and Arts Computing 12: 163-76

Dunae P, Lutz J, Lafreniere D, and Gilliland J 2011 Making the inscrutable, scrutable: Race and space in Victoria's Chinatown, 1891. B.C. Studies 169: 51-80

Elwood S 2009a Geographic Information Science: New geovisualization technologies - emerging questions and linkages with GIScience research. Progress in Human Geography 33: 256-63

Elwood S 2009b Multiple representations, significations, and epistemologies in community-based GIS. In Cope M and Elwood S (eds) Qualitative GIS: A Mixed Methods Approach. London, Sage Publications: 57-74

Gaffield C 2007 Conceptualizing and constructing the Canadian Century research infrastructure. Historical Methods 40: 54-64

Gilliland J and Olson S 2003 Montreal, l'avenir du passe. GEOinfo January-February: 5-7

Gilliland J and Olson S 2010 Residential segregation in the industrializing city: A closer look. Urban Geography 31: 29-58

Goad C E 1984 A Catalogue of Fire Insurance Plans Published by Charles E. Goad 1878-1970. London, C.E. Goad

Gregory I, Bennett C, Gilham V, and Southall H 2002 The Great Britain Historical GIS project: From maps to changing human geography. Cartographic Journal 39: 37-49

Gregory I, 2013 Spatial Humanties: Texts, Geographic Information Systems and Places. WWW Document, http://www.lancaster.ac.uk/spatialhum/index.html

Gregory I and Cooper D 2009 Thomas Gray, Samuel Taylor Coleridge and Geographical Information Systems: A literary GIS of two Lake District tours. International Journal of Humanities and Arts Computing 3: 61-84

Gregory I and Hardie A 2011 Visual GISting: Bring together corpus linguistics and geographical information systems. Literary and Linquistic Computing 26: 297-314

Hägerstrand T 1970 What about People in Regional Science? Papers of the Regional Science Association 24: $7-21$ 
Jung J-K 2009 Computer-aided qualitative GIS: A software-level integration of qualitative research and GIS. In Cope M and Elwood S (eds) Qualitative GIS: A Mixed Methods Approach. London, Sage Publications: 115-35

Jung J-K and Elwood S 2010 Extending the qualitative capabilities of GIS: Computer-aided qualitative GIS. Transactions in GIS 14: 63-87

Kemp K 2010 Geographic information science and spatial analysis for the humanities. In Bodenhamer D, Corrigan J, and Harris T (eds) The Spatial Humanities: GIS and the Future of Humanities Scholarship. Bloomington, IN, Indiana University Press: 31-57

Koti F 2010 Confronting sociospatial exclusion on the fringe of Africa's cities using participatory GIS: Lessions from Athi River Town, Kenya. Africa Today 56: 62-82

Krafft T 1993 Reconstructing the North American urban landscape: Fire insurance maps - an indispensable source. Erdkunde Archive for Scientific Geography 47: 196-211

Kunz A and Boehler W 2005 HGIS Germany: An information system on German states and territories from 1820 to 1914 . Historical Geography 33: 145-47

Kwan M-P 2007 Affecting geospatial technologies: Toward a feminist politics of emotion. Professional Geographer 59: 22-34

Kwan M-P 2013 Beyond space (as we knew it): Towards temporally integrated geographies of segregation, health, and accessibility. Annals of the Association of American Geographers 103: 1078-86

Kwan M-P and Ding G 2008 Geo-narrative: Extending geographic information systems for narrative analysis in qualitative and mixed-method research. Professional Geographer 60: 443-65

Kwan M-P and Lee J 2004 Geovisualization of human activity patterns using 3D GIS. In Goodchild M F and Janelle D (eds) Spatially Integrated Social Science. New York, Oxford University Press: 4866

LinkageWiz 2011 LinkageWiz Data Matching Software. WWW Document, http://www.linkagewiz.net

Loebach J and Gilliland J 2010 Child-led tours to uncover children's perceptions and use of neighborhood environments. Children, Youth and Environments 20: 52-90

Logan J, Jindrick J, Shin H, and Zhang W 2011 Mapping America in 1880: The Urban Transition Historical GIS Project. Historical Methods 44: 49-60

Lutz J, Dunae P, Gilliland J, Lafreniere D, and Harvey M 2013 Turning space inside out: Spatial history and race in Victorian Victoria. In Bonnell J and Fortin M (eds) Historical GIS Research in Canada. Calgary, $\mathrm{AB}$, University of Calgary Press: 1-24

Marciano R, Allen R, Hou C-Y, and Lach P 2013 “Big Historical Data” feature extraction. Journal of Map and Geography Libraries 9: 69-80

McMaster R and Noble P 2005 The U.S. National Historical Geographic Information System. Historical Geography 33: 134-36

Mennis J, Mason M, and Cao Y 2013 Qualitative GIS and the visualization of narrative activity space data. International Journal of Geographical Information Science 27: 267-91

Mostern R and Johnson I 2008 From named place to naming event: Creating gazetteers for history. International Journal of Geographical Information Science 22: 1091-108

Nakaya T 2013 Analytical data transformations in space-time region: Three stories of space-time cube. Annals of the Association of American Geographers 103: 1100-06

Nissim M, Matheson C, and Reid J 2004 Recognising Geographical Entities in Scottish Historical Documents. Sheffield, Workshop on Geographic Informational Retrieval, SIGIR 2004

Novak M and Gilliland J 2011 Trading places: A historical geography of retailing in London, Canada. Social Science History 35: 543-70

Olson S and Thornton P 2011 Peopling the North American City: Montreal 1840-1900. Montreal, QC, McGill-Queens University Press

Oswald D 1997 Fire Insurance Maps: Their History and Applications. College Station, TX, Lacewing Press

Piotrowski M 2012 Natural Language Processing for Historical Texts: Synthesis Lectures on Human Language Technologies. San Rafael, CA, Morgan and Claypool

Rambaldi G, Kwaku Kyem P, McCall M, and Weiner D 2006 Participatory spatial information management and communication in developing countries. Electronic Journal of Information Systems in Developing Countries 25: 1-9

Roberts E, Ruggles S, Dillon L, Gardarsdóttir O, Oldervoll J, Thorvaldsen G, and Woollard M 2003 The North Atlantic Population Project. Historical Methods 36: 80-8

Ruggles S 2002 Linking historical censuses: A new approach. History and Computing 14: 213-24

Sager E and Baskerville P (eds) 2007 Household Counts: Canadian Households and Families in 1901. Toronto, ON, University of Toronto Press

Shaw S-L and Yu H 2009 A GIS-Based time-geographic approach of studying individual activities and interactions in a hybrid physical-virtual space. Journal of Transport Geography 17: 141-49 
Sheppard E 1995 GIS and society: Towards a research agenda. Cartography and Geographic Information Systems 22: 5-16

Sheppard E 2005 Knowledge production through critical GIS: Geneology and prospects. Cartographica 40: $5-21$

Southall H, Mostern R, and Berman M-L 2011 On historical gazetteers. International Journal of Humanities and Arts Computing 5: 127-45

Stewart K, Fan J, and White E 2013 Thinking about space-time connections: Spatiotemporal scheduling of individual activities. Transactions in GIS 17: 791-807

St-Hilaire M, Moldofsky B, Richard L, and Beaudry M 2007 Geocoding and mapping historical census data: The geographical component of the Canadian Century Research Infrastructure. Historical Methods 40: 76-91

van Leeuwen M, Maas I, and Miles A 2002 HISCO: Historical International Standard Classification of Occupations. Leuven, Belgium, Leuven University Press

van Leeuwen M, Maas I, and Miles A 2004 Creating a historical international standard classification of occupations: An exercise in multinational interdisciplinary cooperation. Historical Methods 37: 186-97

Yao X and Jiang B 2005 Visualization of qualitative locations in geographic information systems. Cartography and Geographic Information Science 32: 219-29

Yao X and Thill J-C 2006 Spatial queries with qualitative locations in spatial information systems. Computers Environment and Urban Systems 30: 485-502

Yu H 2006 Spatio-temporal GIS design for exploring interactions of human activities. Cartography and Geographic Information Science 33: 3-19

Yu H and Shaw S-L 2011 GIS designs for studying human activities in a space-time context. In Nyerges T, Couclelis H, and McMaster R (eds) The SAGE Handbook of GIS and Society. London, Sage: 251-68 